\title{
The Role of Mathematical Tools in Scientific Phenomenon Explanation - A Guarantee of Reliability or a Pillar of False Credibility?
}

\author{
VLADIMIR DREKALOVIĆ \\ Faculty of Philosophy, University of Montenegro, Danila Bojovića bb, 81400 Nikšić, Montenegro \\ Email: vladimirdr@ucg.ac.me
}

\begin{abstract}
Ever since its beginnings, mathematics has occupied a special position among all sciences, natural, as well as social sciences and humanities. It has not only provided a role model in terms of methodology, particularly when it comes to natural sciences, but other sciences have always relied on mathematics extensively both in their development and for solving various open questions. The beginning of the 21 st century foregrounded the issue of the so-called explanatory role of mathematics in science. However, the reference literature features only a few examples as illustration of this role. This paper aims at showing that those examples, even though they are used for illustrating precisely the same purpose, also illustrate various explanatory scopes which mathematical tools can reach within a scientific explanation. Some of these examples also show how mathematics, unfortunately, provides false credibility to scientific explanations.
\end{abstract}

Keywords: mathematical explanation, indispensability of mathematics to science, Königsberg bridge problem, honeycomb problem, cicada's case

\section{INTRODUCTION}

Mathematics has always had a very special and, in a sense, privileged position among sciences. What have been the reasons for this kind of status of mathematics? Two facts, among others, could help in searching for an answer to this question. Firstly, science has used mathematical tools from the very beginning of its history in order to describe or explain the phenomena it has explored. In that sense, we can speak of the indispensability of mathematics to science, that is, of the incapacity of science to entirely describe or explain the phenomena it deals with without the assistance of mathematics. ${ }^{1}$ Secondly, deduction, as a main tool of mathematics, has often been 'borrowed' not only for constructing natural sciences, but also the so-called

1 When it comes to the indispensability of the mathematics to science, roughly speaking, we can say that there exist two types of indispensability. The first type was described by the traditional so-called QuinePutnam Indispensability Argument (IA) (Putnam 1971: 65), and the second by the so-called Enhanced Indispensability Argument (EIA) (Baker 2009: 613). Historically speaking, the EIA is an 'improved' version of the IA, according to which the role that mathematical objects have in describing and explaining empirical phenomena is reduced to quantification and indexing of the physical objects. In addition to this, the EIA places an emphasis on the indispensability of the explanatory role of the mathematical objects in the empirical science (Drekalović 2016: 281-282). Even though the EIA is a new version of the traditional Platonist argument, it inspires new questions and dilemmas regarding its usefulness to the Platonists. See Drekalović (2018). 
social sciences and humanities. ${ }^{2}$ To construct a science in its own right the methodology of which would be as close to the mathematical methodology as possible has proved to be a persistent tendency whose vitality is enduring. The reason is clear enough: deduction, in its formal sense, represents a sort of guarantee of the stability of the scientific construction.

In relation to the above stated, we would like to point out that mathematics can be used to explain scientific/physical phenomena in different ways. On the one hand, mathematical tools can be used in their full capacity. A physical phenomenon can be explained with all the mathematical tools and without indefiniteness by means of creating a complete mathematization of a physical problem. On the other hand, mathematical tools and methodology can be merely a part of an explanation which is composed of other scientific and mathematical propositions. In the first case, mathematics asserts its exact superiority. In the second case, however, among numerous and various propositions, mathematical tools become only a part of not so certain an explanation. These other types of cases seem to abuse, to some extent, the authority of mathematics, as it becomes invested in a project that may abound in hypotheses which are not quite justifiable. Therefore, the thesis we want to show in this paper is that mathematics is not always a guarantee of the reliability of scientific explanations, as is commonly thought in laymen as well as in professional circles. Moreover, we will show that not only is it not always a guarantee of reliability, but it is sometimes even supportive of the false credibility of scientific explanations, a thesis not easily found in the field of mathematical philosophy. In this work we will use methods of analysis and comparison of concrete examples which are the main illustrations of the so-called explanatory role of mathematics in science.

\section{THREE EXAMPLES - FROM CERTAIN TO A HYPOTHETICAL SCIENTIFIC EXPLANATION}

We will here mention and analyse three examples given in the literature as illustrations of the mathematical explanation in science: Königsberg bridge problem, honeycomb problem and the cicada's case. ${ }^{3}$ We have chosen precisely these in order to show how varied the role of mathematics could be in scientific explanation. ${ }^{4}$ These examples will point to the fact that the role which mathematics can have in an explanation within a science cannot be represented by the two discrete and extreme situations mentioned in the introduction, but that different grades of in-between cases could be found, containing more or less elements of either one or the other of the extremes.

In the Königsberg bridge problem (KBP), a specific physical phenomenon was entirely explained by means of mathematical tools (Fig. 1). It is a problem that dates back to the 18th century and which Euler solved by graph theory. The question was: Is it possible to cross all seven Königsberg bridges once and only once ending the trip at the same place where it had started ${ }^{5}$ Euler solved the problem in a typically mathematical manner. He represented all the objects that were of relevance to the solution (bridges and parts of the land) by a mathematical object - a graph - in the same order in which they exist in the physical world.

2 These ideas were promoted, among others, by the Vienna Circle philosophers and Positivism sociologists between the two World Wars.

3 See Pincock (2012).

4 The topic of varying explanatory degrees of mathematics in science has been addressed by several other authors. See, for example, Friend \& Molinini (2016).

5 For more details, see, for instance, Lovász et al. (2003: 135-139). 


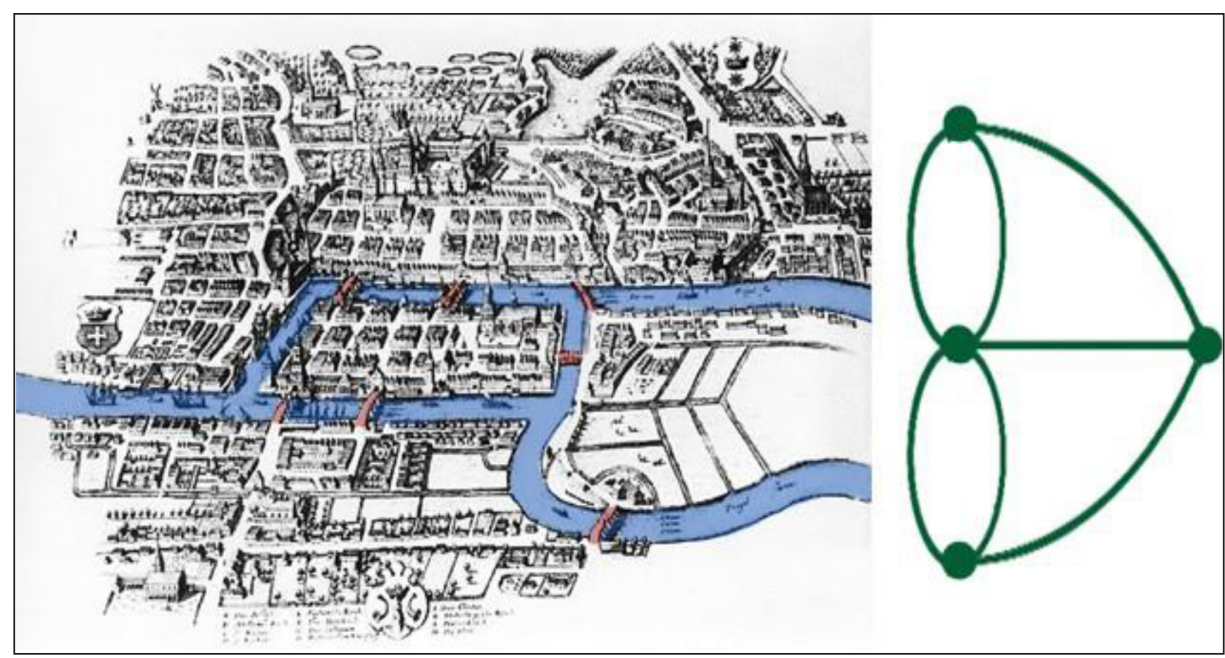

Fig. 1. Bridges of Königsberg and Graph Theory ${ }^{6}$

In that way, he reduced a physical situation and a solution to the problem occurring in it to a purely mathematical level. A complete mathematization of the problem was carried out. The bridges, as well as land areas and Königsberg buildings, as well the river, were no longer relevant to solution of the problem. The land areas were represented by the vertices and the bridges by the edges. None of the physically concrete details were needed in order to solve the problem. It was 'extracted' from its physical context and transported into the mathematical context. Following its solution within the mathematical environment, the explained and solved problem should then be brought back into its physical reality. ${ }^{6}$ In the explanation of this type, the hands of the mathematician remain entirely 'clean' throughout the process, as they are unblemished and untouched by any empirical and physical details and propositions. The mathematician is left to do his work in his own field of expertise. Hence, in a nutshell, we can say that in the above example a physical problem was solved and explained only and exclusively by means of the mathematical tools. It should also be noted that the process of solving it was not conditioned by any hypotheses whatsoever, whether justifiable or not, empirical or mathematical.

The second problem, the so-called honeycomb problem (HP), is even older than the previous, but, unlike the previous, it has been solved only recently (Fig. 2). It concerns the fact that the honeycomb cells are in the form of regular hexagon and, consequently, the question naturally arises: Is there a reason why, in their architecture, the bees should have chosen that polygon in particular if we accept the theory of evolution, and not, for example, an equilateral triangle, a square, or another shape different from the hexagon, or any other combination of different convex or concave polygons?

${ }^{6}$ On the basis of the theorem from the graph theory which examines necessary and sufficient conditions for the mentioned moving in an arbitrary graph, the answer to the question asked in KBP is negative. For more information, see, for example, Diestel (2005: 21-22). 


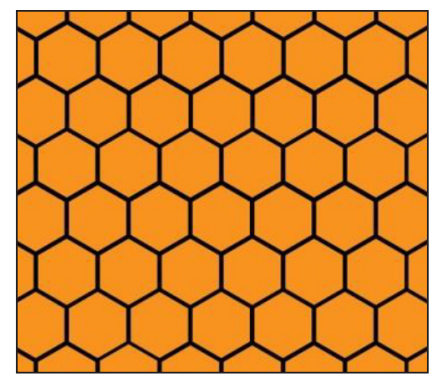

Fig. 2. Honeycomb Pattern Background ${ }^{8}$

As this question includes geometrical concepts, mathematicians were naturally expected to take part in the quest for the answer. After a long period of waiting, it finally arrived about twenty years ago. ${ }^{7}$ Namely, it turned out that the most 'economical' way to cover an area by polygons is the one in which the basic units will be precisely the regular hexagons. The circumference formed by the basic units thus chosen is the optimal option when compared to all other possible polygon units having the same surface. Taking into consideration the evolutionist idea that the species with the most efficient mode of life organization will have the highest odds of survival, we come to the explanation of the honeycomb problem. The groups of bees that spend the least amount of wax, time and energy for building their natural habitat are more likely to survive than other groups belonging to the same type of insect. ${ }^{8}$

We must notice that, unlike the explanation of the KBP, the HP explanation is not purely mathematical. To be more precise, it is composed of two parts, none of which could provide explanation alone and independently from the other. The mathematical component of the explanation solves in the exact manner the question of the optimal solution concerning the least possible circumference of the basic units used in the insects' production of honeycomb. In that sense, the answer is precise and with no additional options. This part of the explanation is not, however, sufficient and cannot explain why the bees, being animals and hence, presumably, not able to consider problems theoretically as people do, choose such a mode of organizing their habitat. That is why another proposition was necessary: a biological, evolutionist assumption about the better survival prospects of those species that adjust better to natural conditions. In this case, that would imply minimal/optimal consumption of one's own biological resources. Therefore, the offered HP explanation is based on exact mathematical assessment of the optimal size selection, as well as on the evolutionist hypothesis that constitutes a biological theory of the development of living species. ${ }^{9}$

Finally, the third explanation of scientific phenomenon which employs mathematical tools, as mentioned in this paper, is the so-called cicada's case (CC). This unusual phenomenon

7 There are testimonies stating that this problem was tackled even by Pappus of Alexandria (III-IV century AD) and Marcus Terentius Varro (1st century BC). Its solution, however, was not published until 1999 by Thomas C. Hales (the so-called Honeycomb theorem). According to Hales, even mathematicians before Varro had been familiar with the problem. For more information, see: Varro (1934), Pappus d'Alexandrie (1982) and Hales (2001).

8 In addition to Hales (2001), for further explanation of this problem see Fejes (1964a), Fejes (1964b), Morgan (1999) and Weyl (1952).

9 Of course, today, there are various scientific theories that support arguments against evolution (Numbers 2006; Behe 1996; Fodor and Piattelli-Palmarini 2010, etc.). 
was detected by biologists in the first half of the 20th century; however, it found its place in the philosophy of mathematics at the beginning of this century. ${ }^{10}$ This North-American type of cicadas (Magicicada) has life cycles which are repeatedly and incessantly renewed. After they are born, these animals live first underground, as larvae, for 13 or 17 years. After that, they emerge to daylight, they mate, reproduce and die. Their successors continue and repeat the same life-cycle. What attracted a special attention is the fact that the duration of their life-cycles is always stated in prime numbers. A probability for the occurrence of such a random event is extremely small. ${ }^{11}$ One of the explanations of this biological phenomenon includes elementary facts from number theory. Namely, since prime number is divisible only by 1 and by itself, the cicada whose life-cycle is stated by a prime number has better chances to survive than the cicada whose life-cycle is stated by a composite number. Why is that? For example, the cicada whose life-cycle would last 18 years would have a chance to meet potential predators whose life-cycles last for 1, 2, 3, 6, 9 or 18 years, whereas the cicada whose life-cycle is 17 years long would have a chance to meet only those predators whose life-cycles are 1 or 17 years long. Drawing on the specific evolutionist assumption, we can explain the natural phenomenon from the above. According to this assumption, the natural selection results in disappearing of the organisms that are less adjusted to the life conditions - in this case: organisms whose odds for meeting with predators are higher. By means of various mutations throughout generations, these organisms tend to become more similar to the organisms that are better adapted to the environment.

The analysis of this phenomenon in the philosophy of mathematics has a relatively brief, although productive history, throughout which there have been various modifications in the explanation, created with the aim of rendering it more reliable and more probable. Thus, for example, it records the employment of rather feeble propositions, such as the one that assumes that the biologically acceptable interval in which it is reasonable to look for a natural number expressing the duration of the cicada's life-cycle is [12, 18] (Baker 2016: 338), [6, 28] (Baker 2017: 784), or the one which proposes that the cycle must be stated in natural number in the form of $4 n+1$ (Baker 2017: 783). Eventually, all the versions of the explanation contain the least justifiable among the mentioned hypotheses - the one about the existence of periodical predators, which, however, has not been recorded so far in any of the biological literature (Behncke 2000: 417). Unless this hypothesis is accepted, all the versions of the explanation become more speculations than rational explanations of a natural phenomenon.

\section{ANALYSIS OF THE EXPLANATIONS}

We have recalled the three examples from the literature in order to illustrate the use of mathematical explanation in science. These examples demonstrate that the role of mathematical tools in those kinds of explanations can be different. There are authors who argue that the essential difference between the explanations of the KBP and the CC is contained in the fact that the former is 'intra-mathematical' and the latter is 'extra-mathematical', associating the first attribute to the so-called explanatory mathematical proof, whereas the meaning of the second attribute remains somewhat unexplained (Colyvan 2018). Generally speaking,

\footnotetext{
10 See Howard (1937) and Baker (2005).

11 Probability that a randomly chosen natural number from, say, segment $[8,20]$ will be prime number is approximately 0.3 . Probability that both out of the two numbers chosen in the same way will be prime numbers is approximately 0.1 .
} 
this terminology appears to be in line with the analysis of mathematical explanations in science. Nevertheless, we still think that an additional, more distinctive and a clearer analysis of the meaning of these attributes is required.

Roughly speaking, all the explanations in science which employ mathematical tools could be divided into two groups regarding the role mathematics plays in them. The first group would contain those explanations in which a complete mathematization of a physical/ natural phenomenon was performed. By the term mathematization we refer to a process in which a specific phenomenon, with all its relevant physical entities, the relations among them included, has been isomorphically mapped onto the respective mathematical structure. ${ }^{12}$ From the moment mathematization of a phenomenon is completed, the explanation is no longer conditioned by scientific propositions. The explanation is thereof constructed only in mathematical context and by mathematical tools. No (un)proved hypotheses can affect the alterations within it. The only subsequent connection that this kind of explanation can have with the 'external' world is the moment in which the solution to the mathematical problem is to be transferred back to the physical world by means of inverse isomorphism, the moment when the solution/explanation of the initial physical phenomenon is to be recognized. In this sense, such an explanation of an empirical phenomenon can justly be named intra-mathematical. The KBP explanation is the example of such an explanation.

The second group of explanations could contain all the explanations in which it is not entirely possible to 'code' scientific phenomenon by a mathematical structure. In these cases, the explanation is not reached by means of mathematical tools exclusively, but results from various mathematical as well as non-mathematical facts and propositions. This kind of explanation is not carried out in a purely mathematical context and strictly within a mathematical theory. It is not free from the scientific hypotheses that can affect the process of creating the explanation. On the contrary, the mathematical tools are used only to a certain extent and at certain points, merely to assist and support the scientific hypotheses, which remain the main guidelines in the explanation. Bearing this in mind, we call these explanations extra-mathematical. The examples are the HP and the CC explanations. Colyvan tried to show that the first of three examples illustrates the so-called intramathematical explanation (explanation by which a mathematical fact is explained by means of mathematical facts), and the other two are the so-called extramathematical explanations (explanations in which a physical phenomenon is explained by means of mathematical facts). We want to underline that all three cases are about a mathematical explanation of a physical fact/phenomenon, and that methodological differences between the cases depend only on the extent to which mathematical explanation is used in a scientific explanation. In other words, the attributes of intramathematical and extramathematical may in this context be assigned to explanations not on the basis of the object of explanation (it is always a physical phenomenon, which Colyvan does not notice) but on the degree of involvement of mathematical explanation in scientific explanation. In doing so, the attribute intramathematical makes sense to assign only to an explanation that is fully mathematized, free from the influence of any uncertain empirical hypotheses.

The three aforementioned explanations are often cited with the same purpose. They illustrate mathematical explanation in science. We can find them in Pincock (2012), Colyvan (2018), Baker (2016), etc. However, none of the three authors mentioned indicated the specific differences and reliability of each of these examples. In addition, none of the authors

\footnotetext{
${ }^{12}$ More precise definition of this sort of mapping can be found in Drekalović (2019).
} 
pointed to the misuse of mathematics, the fact that mathematics provides false credibility to explanations that use problematic empirical hypotheses. We want to point out just such details in our paper. Namely, they disclose the difference that may exist in explanations when it comes to methodology of using mathematical tools for explaining a scientific phenomenon. The fact that there exist differences directly affects reliability of scientific explanations. Indeed, in the KBP explanation the entire physical phenomenon is coded in mathematical objects of the graph theory. The solution to the problem is thus completely transferred into the hands of mathematicians, without a risk that the rest of the process might be rendered disputable by a new empirical hypothesis, possibly created by an appearance of new evidence or further advances in the science. Therefore, the explanation of the phenomenon is empirically 'frozen' until the mathematical analysis is completed. This kind of methodology and this kind of role mathematical analysis has in an explanation allows for the mathematics to demonstrate its potential and its capacity to the fullest. With no room for errors and dilemmas of any kind, with utmost exactness and precision, it helps solve a specific problem. The physical problem in this case assumes a new form. It becomes a mathematical problem. However, as we tackle the HP and, subsequently, the CC as well, the position and significance of the mathematical tools are changed. They assume a different role in the entire process of explanation. In the last two cases, not only is it impossible to speak of a total mathematization of the empirical phenomenon, but, furthermore, the mathematical propositions and facts become merely a part of the phenomenon's explanation. In the HP explanation, the Honeycomb theorem and the evolutionist hypothesis are joined to make the main body of the explanation. The problem has not been entirely mathematicized, but the Honeycomb's theorem is nevertheless crucial. It explains the optimal shape of the honeycomb unit. With the aid of the biological assumptions about the adaptation and selection of the species, we arrive at the explanation of the phenomenon. However, should the evolutionist assumption become, for any reason whatsoever, disputed at some point, the mathematical attempts would not be sufficient to provide the explanation for the phenomenon, at least not at the present moment.

Eventually, in the CC explanation, when compared to the previous two examples, the role of the mathematical arguments can be said to be considerably marginalized. Within a myriad of biological assumptions that have their own evolution and many of which have not been clearly justified at that, the mathematical facts seem to be there merely for the sake of filling in the void between those assumptions. Since the role and the significance of the mathematical position in explaining an empirical phenomenon are transformed as we move from the KBP towards the HP and then to the CC, we can say that reliability of these explanations is also transformed to the same extent. As far as the KBP is concerned, we are assured of the complete reliability of the explanation. The explanation of the HP will be doubted only by those who doubt the theory of evolution. At last, the CC provides no certainty, as a possibility of a new scientific hypothesis could shake all the previous versions of the mathematical explanation of the phenomenon. In Baker's papers (Baker 2009; Baker 2016; Baker 2017) we can trace the development, as well as ad hoc change of argumentation, which seems to be 'fixed' and adjusted to make the CC explanation more justifiable as a whole. It seems to us that Baker has set himself the goal of defending a concrete scientific explanation by mathematical means at all costs, without taking into account the justification of the empirical assumptions he chooses, which generally creates a bad image of the CC explanation. Baker is in the role of a poor student who thinks he knows the final solution to a mathematical problem and tries in every way, without choosing the validity of the aids, to arrive at that solution. 


\section{CONCLUSIONS}

The three examples analysed here underline a gradation of roles that a mathematical explanation can have within a scientific explanation. Generally speaking, the very authority of mathematics in the constellation of all sciences - natural, as well as social and humanities - is such that the mere presence of a mathematical explanation in an explanation of a scientific phenomenon can lead one toward an incorrect conclusion. It is a conclusion about the doubtless reliability of such a scientific explanation. The third of the examples analysed in this paper, which abounds in uncertain hypotheses, is a demonstration that such a conclusion cannot be accepted without reservation. Presence of a mathematical explanation within an explanation of a scientific phenomenon is not a guarantee of reliability of the explanation. The measure of reliability, as we could see from the examples analysed here, is conditioned by the role and function of the mathematical tools employed in the explanation. A complete mathematization of an empirical phenomenon creates a possible way toward a complete reliability of the explanation. Mathematization establishes a model - mathematical, abstract - that thoroughly represents a specific empirical phenomenon in the mathematical context. In that respect, it is useful to consider the scope and general applicability of this kind of methodology to physical phenomena explanations. The main open question that emerges in this only partially examined area is the following: What are the conditions, generally speaking, that determine a possibility of the complete mathematization of an empirical phenomenon? Regardless of our remoteness from or closeness to the answer to this question, it is obvious from the examples analysed above that a mere employment of the mathematical explanation in science does not guarantee reliability of the scientific explanation. As we have seen, in some of the cases the employment displays the full power of the mathematical explanation - it helps to arrive at the reliable scientific/physical explanation. In some other cases, however, the use of mathematical explanation becomes rather an 'abuse' of the authority of mathematics, as it serves as a formal decoration aimed at making an explanation which is full of uncertain hypotheses appear more reliable than it really is. Moreover, an analysis of the last of our three examples has shown that a mathematical tool is sometimes used to provide false credibility to unconvincing scientific explanations that abound in uncertain hypotheses. In these cases, mathematics is only used to close the many cracks that exist in such explanations. This role of mathematics does nothing to preserve its authority, which has been built for centuries. In pointing out this misuse of mathematics, we had no ambition to list all possible cases of this kind but wanted to point out a potential problem that may exist in the explanatory field of any science.

Received 24 December 2019

Accepted 11 February 2020

\section{References}

1. Baker, A. 2005. 'Are There Genuine Mathematical Explanations of Physical Phenomena?', Mind 114(454): 223-238.

2. Baker, A. 2009. 'Mathematical Explanation in Science', British Journal of Philosophy of Science 60(3): 611-633.

3. Baker, A. 2016. 'Parsimony and Inference to the Best Mathematical Explanation', Synthese 193(2), 333-350.

4. Baker, A. 2017. 'Mathematical Spandrels', Australasian Journal of Philosophy 95(4), 779-793.

5. Behe, M. 1996. Darwin's Black Box: The Biochemical Challenge to Evolution. New York: Free Press.

6. Behncke, H. 2000. 'Periodical Cicadas', Journal of Mathematical Biology 40(5), 413-431.

7. Colyvan, M. 2018. 'The Ins and Outs of Mathematical Explanation', The Mathematical Intelligencer 40(4), 26-29.

8. Diestel, R. 2005. Graph Theory. New York: Springer-Verlag Heidelberg. 
9. Drekalović, V. 2016. 'Two Weak Points of the Enhanced Indispensability Argument - Domain of the Argument and Definition of Indispensability', Organon F 23(3), 280-298.

10. Drekalović, V. 2018. 'Is the Enhanced Indispensability Argument a Useful Tool in the Hands of Platonists?', Philosophia 47(4), 1111-1126.

11. Drekalović, V. 2019. 'The Mathematical Explanation as Part of a (im)Perfect Scientific Explanation - Analysis of Two Examples', Filozofia Nauki 27(4) (forthcoming).

12. Fejes, L. T. 1964a. Regular Figures. New York: MacMillan.

13. Fejes, L. T. 1964b. 'What the Bees Know and What They do not Know', Bulletin of American Mathematical Society 70(4), 468-481.

14. Fodor, J.; Piattelli-Palmarini, M. 2010. What Darwin Got Wrong. New York: Farrar, Straus and Giroux.

15. Friend, M.; Molinini, D. 2016. 'Using Mathematics to Explain a Scientific Theory', Philosophia Mathematica 24(2): 185-213.

16. Hales, T. C. 2001. 'The Honeycomb Conjecture', Discrete and Computational Geometry 25(1), 1-22.

17. Howard, W. J. 1937. 'Bird Behavior as a Result of Emergence of Seventeenyear Locusts', Wilson Bulletin 49(1), 43-44.

18. Lovász, L.; Pelikán, J.; Vesztergombi, K. 2003. Discrete Mathematics. New York: Springer.

19. Morgan, F. 1999. 'The Hexagonal Honeycomb Conjecture', Transactions of the American Mathematical Society 351(5), 1753-1763.

20. Numbers, R. L. 2006. The Creationists: From Scientific Creationism to Intelligent Design. Cambridge, Mass.: Harvard University Press.

21. Pappus d'Alexandrie. 1982. La collection mathématique. Transl. by P. Ver Eecke, A. Blanchard.

22. Pincock, C. 2012. Mathematics and Scientific Representation. Oxford: Oxford University Press.

23. Putnam, H. 1971. Philosophy of Logic. New York: Harper \& Row.

24. Varro, M. T. 1934. On Agriculture. Transl. by W. D. Hooper, H. B. Ash. Loeb Classical Library. Cambridge, Mass.: Harvard University Press.

25. Weyl, H. 1952. Symmetry. Princeton, NJ.: Princeton University Press.

\title{
Matematinių priemonių vaidmuo aiškinant socialinius reiškinius - tikro patikimumo garantas ar tariamo patikimumo priedanga?
}

\begin{abstract}
Santrauka
Nuo pat susiformavimo pradžios matematika mokslų sistemoje, aprépiančioje tiek gamtos, tiek ir socialinius bei humanitarinius mokslus, užèmė ypatingą vietą. Viena vertus, ji teikè mokslams sektiną metodologinị modelį. Tai ypač aktualu gamtos mokslams. Antra vertus, kiti mokslai visada remèsi matematika tiek plètodami savo teorijas, tiek ir spręsdami ịvairiausius klausimus. 21 a. pradžioje iškilo vadinamoji aiškinamojo matematikos vaidmens moksluose tema. Analitinejje literatūroje galima atrasti keletą aiškinamąji matematikos vaidmenį iliustruojančių pavyzdžių. Straipsnyje siekiama parodyti, kad tie pavyzdžiai, nors ir naudojami tuo pačiu tikslu, taip pat atskleidžia matematinių skaičiavimų mokslinio aiškinimo ribas. Be to, kai kurie, pavyzdžiui, kaip matematika, moksliniam aiškinimui suteikia, deja, ir tariamą patikimumą.
\end{abstract}

Raktažodžiai: matematinis aiškinimas, matematikos būtinumas moksle, Karaliaučiaus tilto problema, korio problema, cikados atvejis 